\title{
Fresh embryos versus freeze-all embryos - transfer strategies: Nuances of a meta-analysis
}

Felipe C Dieamant ${ }^{1,2}$, Claudia G Petersen ${ }^{1,2}$, Ana L Mauri ${ }^{1,2}$, V. Comar ${ }^{1}$, Mariana Mattila ${ }^{1}$, Laura D Vagnini ${ }^{2}$, Adriana Renzi ${ }^{2}$, Bruna Petersen ${ }^{2}$, Andreia Nicoletti ${ }^{1}$, João Batista A Oliveira ${ }^{1,2}$, Ricardo LR Baruffi ${ }^{1,2}$, Jose G Franco $\mathrm{Jr}^{1,2}$

${ }^{1}$ Center for Human Reproduction Prof. Franco Jr., Ribeirão Preto, Brazil

2Paulista Center for Diagnosis, Research and Training, Ribeirão Preto, SP, Brazil

This study was presented at the $33^{\text {th }}$ annual meeting of ESHRE 2017, in Geneva, Switzerland

\section{ABSTRACT}

Objective: The present meta-analysis aimed to evaluate whether the freeze-all strategy (Freeze/All-ET) could bring about improvements in the clinical assisted reproductive technique (ART) outcomes when compared with the fresh embryo transfer strategy (Fresh-ET) in patients undergoing an ART cycle in accordance with the mean number of oocytes collected.

Methods: A systematic review based on electronic searches in databases (PubMed, EMBASE, Web of Science, SCOPUS, and Cochrane Central Register of Controlled Trials) was carried out to identify randomized controlled trails (RCTs) comparing ART outcomes between fresh-embryo transfers versus elective frozen-embryo transfers up to February of 2017. Four reviewers independently evaluated abstracts, validity assessment and data extraction. Odds Ratio (OR) values with a 95\% confidence interval (CI), and heterogeneity were evaluated.

Results: Five RCTs were included as targets for data extraction and meta-analysis purposes. The results of this meta-analysis were divided into two parts (Freeze/AllET versus Fresh-ET): Part I- All trials in which the mean number of collected oocytes was $>12$ and $<21$ for ongoing pregnancy rate $(\mathrm{OR}=1.24 ; 95 \% \mathrm{CI}=1.06-1.44)$, clinical pregnancy rate $(\mathrm{OR}=1.19 ; 95 \% \mathrm{CI}=0.98-1.43)$, live birth rate $(O R=1.39 ; 95 \% C I=0.99-1.95)$, and miscarriage rate $(\mathrm{OR}=0.68 ; 95 \% \mathrm{CI}=0.46-1.00)$; Part II- Three studies where the mean number of oocytes retrieved was $>12$ and $<15$ for ongoing pregnancy rate $(\mathrm{OR}=1.17 ; 95 \% \mathrm{CI}=1.00-$ $1.38)$, clinical pregnancy rate $(\mathrm{OR}=1.34 ; 95 \% \mathrm{CI}=0.79$ $2.28)$, live birth rate $(\mathrm{OR}=1.24 ; 95 \% \mathrm{CI}=1.00-1.55)$, and miscarriage rate $(\mathrm{RR}=0.68 ; 95 \% \mathrm{CI}=0.46-1.02)$.

Conclusions: The freeze-all strategy could be favorable when high numbers of oocytes are collected, signaling an association between higher ovarian stimulation and consequent impairment of endometrial receptivity. However, when the mean number of oocytes collected is $<15$, the freeze-all strategy does not appear to be advantageous.

Keywords: Freeze-all embryos, fresh-embryo transfer, ovarian stimulation, endometrial receptivity, IVF/ICSI, meta-analysis

\section{INTRODUCTION}

The Freeze-all strategy (Freeze/All-ET), which consists of the cryopreservation of all embryos from an assisted reproductive technique (ART) cycle, and delayed embryo transfer in a natural cycle or a programmed hormone replacement cycle to prepare the endometrium, which is considered the preferred way to avoid potential deleterious effects of controlled ovarian stimulation (COS) during freshembryo transfer (Fresh-ET) on endometrium receptivity, and consequently on embryonic implantation (Silverberg et al., 1994; Shapiro et al., 2008). COS is associated with negative effects on endometrial receptivity during ART cycles, probably due to high levels of estrogen $(E)$ and progesterone $(P)$ during the follicular phase compared to natural cycles (Kolibianakis et al., 2002; Bosch et al., 2003; Venetis et al., 2013; Huang et al., 2015). Because of subtle elevations of $\mathrm{P}$ during COS, there could be a consequent asynchrony between the endometrium and the transferred embryos; probably the endometrial development should be at an advanced stage at the moment of embryonic implantation (Nikas, 1999; Wong et al., 2014). Therefore, it's known that the best results in ART, considering pregnancy rates, are found in oocyte donation cycles and cycles using frozen-thawed embryos transfer (FET) (Murata et al., 2005; Richter et al., 2006; Shapiro et al., 2009; Kansal Kalra et al., 2011). A plausible explanation for this is the fact that the endometrium is artificially primed, without COS and supraphysiological hormonal levels at the time of the embryo transfer (Melo et al., 2006; Venetis et al., 2013). In addition, it has been reported that patients with high ovarian reserve, e.g. high-risk of ovarian hyperstimulation syndrome (OHSS), and polycystic ovarian syndrome (PCOS) patients, could benefit from the Freeze/All-ET (Griesinger et al., 2007; Griesinger et al., 2011).

The aim of the present systematic review and metaanalysis is to evaluate whether Freeze/All-ET could bring about improvements in the clinical ART outcomes when compared with Fresh-ET in patients undergoing the ART cycle, in accordance with the mean number of oocytes collected.

\section{MATERIALS AND METHODS}

\section{Identification of studies}

We ran a systematic review based on electronic searches in the following databases (PubMed, EMBASE, Web of Science, SCOPUS, and Cochrane Central Register of Controlled Trials), up to February of 2017, to identify randomized controlled trials (RCTs) comparing ART outcomes of Freeze/All-ET versus Fresh-ET. The search was restricted to papers published in English. The following medical subject headings and text words were used: "IVF", "ICSI", "freeze-all", "frozen-thawed embryos", "frozen-embryo transfer", "fresh-embryo transfer", "poorresponder", "normal-responder", "high-responder", "clinical outcomes", "oocytes collected", and "randomized study". The main inclusion criterion was a randomized controlled trial (RCT). ysis

Criteria for including studies in this meta-anal-

All available published and ongoing randomized controlled trials comparing clinical outcomes between patients undergoing IVF/ICSI cycles with Freeze/All-ET or Fresh-ET were included. All trials provided data on IVF cycles, including number of oocytes retrieved. 


\section{Outcome measures}

The primary outcome measure for this metaanalysis was the ongoing pregnancy rates (per woman, randomized). Secondary outcomes included clinical pregnancy rates (per patient randomized) and miscarriage rates (from clinical pregnancy). Clinical pregnancy was defined as the presence of a gestational sac in the uterine cavity (with or without a heartbeat) at 6/7 gestation week, detected by ultrasonography. Ongoing pregnancy was defined as the presence of a fetus with heart motion at 10 to 12 weeks of gestation. Miscarriage was considered any pregnancy - clinical pregnancy - that did not achieve ongoing pregnancy status. In addition, live birth rates defined as the delivery of a live-born infant after 25 weeks of gestation was included as secondary outcomes.

\section{Validity assessment and data extraction}

Each trial was assessed independently by four reviewers (FCD, JBAO, RLRB and JGF), and ranked for its methodological rigor and its potential for the introduction of biases. Originally reported characteristics, including a method for randomization, the presence of a power calculation, the unit of analysis used, and the presence or absence of examiner blinding were analyzed. Missing data were obtained from the authors.

\section{Statistical analysis}

Five RCTs were included as targets for data extraction and meta-analysis. The data was combined for metaanalysis using the Stats-Direct statistical software. Dichotomous data was expressed as Odds Ratio (OR) with a $95 \%$ confidence interval (CI). The measure of heterogeneity was evaluated using Cochran's $Q$ and $\mathrm{I}^{2}$. The heterogeneity was considered high when $I^{2} \geq 50 \%$. The study data was combined using a fixed-effects model when the heterogeneity among the trials was considered low or statistically insignificant ( ${ }^{2}$ was $<50 \%$ ). However, the random-effects model was employed when the heterogeneity was considered substantial $\left(\mathrm{I}^{2} \geq 50 \%\right)$, and when $\mathrm{I}^{2}$ was not applicable (NA). $P$-values $<0.05$ were considered statistically significant.

The present meta-analysis was reported following the Preferred Reporting Item for Systematic Reviews and Meta-analyses (PRISMA) statement (S1 File).

\section{RESULTS}

\section{Study selection and characteristics}

Among the 72 potentially relevant studies found, a total of five trials fulfilled the inclusion criteria (Shapiro et al., 2011a; Shapiro et al., 2011b; Chen et al., 2016; Vuong et al., 2016; Coates et al., 2017). A flow diagram of the selection process is depicted in Figure 1. From the studies included, 2,728 patients were enrolled; 1,358 in the Freeze/All-ET group and 1,370 in the Fresh-ET group. The sample sizes of the included trials ranged between 60 and 762 women. The main characteristics and description of the five RCTs included in this meta-analysis are shown on Table 1 and the literature-exclusion procedures are available in Figure 1.

\section{Systematic Review}

Shapiro et al., 2011a (High-responder): A prospective randomized trial was performed to assess potential effects of COS on endometrial receptivity. It was published, as correspondence, thus complete data on methods were not evaluated ("not-randomized", "not-blind", "no-power calculation" descriptions). Clinical pregnancy rates per transfers in Freeze/All-ET cycles and Fresh-ET were compared. The inclusion criteria were patients undergoing their first IVF cycle, day $3 \mathrm{FSH}$ cycle $<10 \mathrm{IU} / \mathrm{L}$, and $>15$ antral follicle-count. This study involved 131 patients, and
122 were randomized ( 62 to the fresh group and 60 to the cryopreservation group). The two groups were similar in age, antral follicle count, days of stimulation (10.4 versus 10.6), mean number of oocytes retrieved for Freeze/All-ET

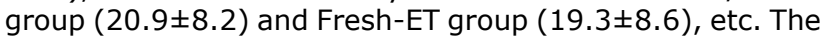
ongoing pregnancy rates per retrieval were $63.3 \%(38 / 60)$ in the Freeze/All-ET group and $54.8 \%(34 / 62)$ in the FreshET group $(p=0.36)$. Regression logistics was performed to check for potential differences in clinical outcomes while controlling for embryo quality. They found that a greater likelihood of clinical pregnancy was associated with the Freeze/All-ET group ( $p=0.0037)$.

Shapiro et al., 2011b (Normo-responder): In this prospective randomized study of 137 patients undergoing their first IVF cycle in which they had 67 and 70 oocytes retrieved in the Fresh-ET and Freeze/All-ET groups, respectively, the authors compared success rates between Fresh-ET after ovarian stimulation and Freeze/All-ET after artificial endometrial preparation - to compare endometrial receptivity. A two-stage, two-sided group sequential procedure with an overall type I error of.05 was used, to test the primary hypothesis of a difference in the probabilities of clinical pregnancy for the two arms in this study, with a maximum sample size of 411 patients needed to achieve $80 \%$ power for detecting a difference of $15 \%$ in the clinical pregnancy rate (sample size not reached). Patients were randomized by drawing randomly among identical, opaque, unmarked sealed envelopes (there was no blind description). The two groups were similar in age, diagnosis, baseline serum FSH level, antral follicle count, days of stimulation (10.5 versus 10.4), mean number of

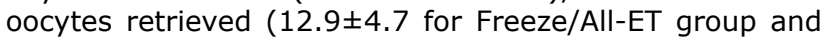
$14.1 \pm 6.4$ for Fresh-ET group), etc. Both groups did not differ significantly in number of transferred blastocyst or endometrial thickness on the trigger day. There were no significantly greater rates of clinical pregnancy per randomized patient $(60.0 \%$ versus $43.3 \%)$, ongoing pregnancy per randomized patient ( $55.7 \%$ versus $40.3 \%$ ), and no significant lower miscarriage rate from clinical pregnancy (14.3\% versus $24.1 \%$ ) in the Freeze/All-ET group. Patients with extreme high responses were taken off the study.

Chen et al., 2016: assessed 1,508 infertile women with PCOS, who were randomized during their first IVF cycle to undergo either Fresh-ET $(n=762)$ or Freeze/AllET $(n=746)$. The patients were randomly assigned to one of the two study groups in a $1: 1$ ratio, using an online central randomization system, which was unknown to the clinical investigators. Both groups had similar IVF cycle characteristics, including age, endometrial thickness, days of stimulation (10.3 versus 10.3) and number of oocytes retrieved $(14.4 \pm 6.0$ for the Freeze/All-ET group and $14.2 \pm 5.8$ for the Fresh-ET group). They found that the Freeze/All-ET group achieved significantly higher live births rate $(49.3 \%$ versus $42.0 \%)$; higher, but not significant, clinical pregnancy rates $(58.7 \%$ versus $56.2 \%)$ and ongoing pregnancy rates $(52.7 \%$ versus $48.8 \%)$. On the other hand, miscarriage rates (from clinical pregnancies) were significantly lower in the Freeze/All-ET group (14.6\% versus $25.0 \%$ ). The authors also compared perinatal outcomes.

Vuong et al., 2016: In this randomized study, the aim was to compare the effectiveness of the Freeze/AllET to conventional Fresh-ET in non-PCOS women. The inclusion criteria were: had $\leq 1$ previous IVF cycle, could have embryo transfer on day 3 , had at least 1 top-quality embryo. On the other hand, the exclusion criteria were: PCOS and oocyte donation. The days of stimulation were similar between the Freeze/All-ET and the Fresh-ET groups (9.16 versus 9.14). Randomization (1:1) was made by a 


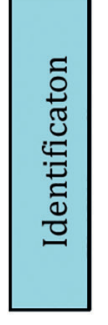

Potentially trials identified and screened for retrievel $(n=72)$

Trials excluded: Non-comparative studies $(n=60)$
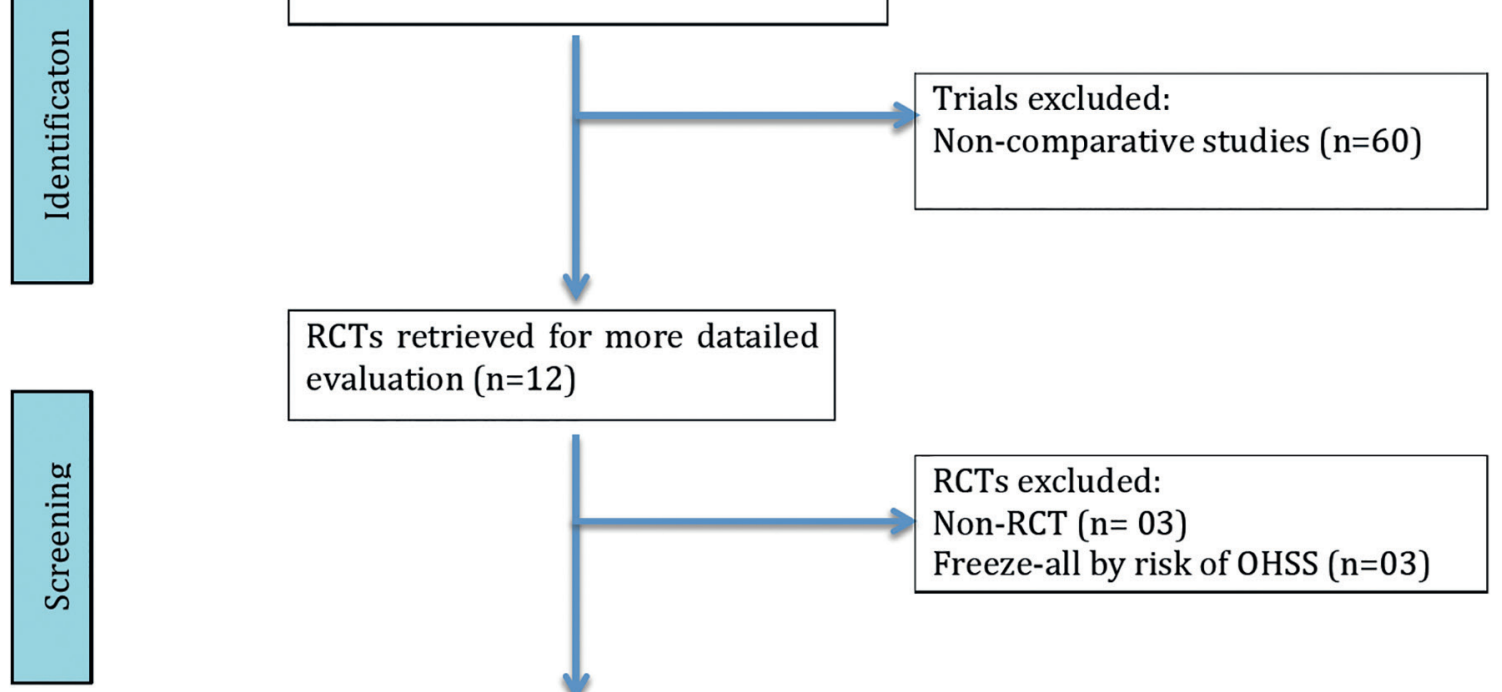

RCTs excluded:

Non-RCT $(\mathrm{n}=03)$

Freeze-all by risk of OHSS $(\mathrm{n}=03)$

Potentially appropriate RCTs to be included in the meta-analysis $(\mathrm{n}=06)$
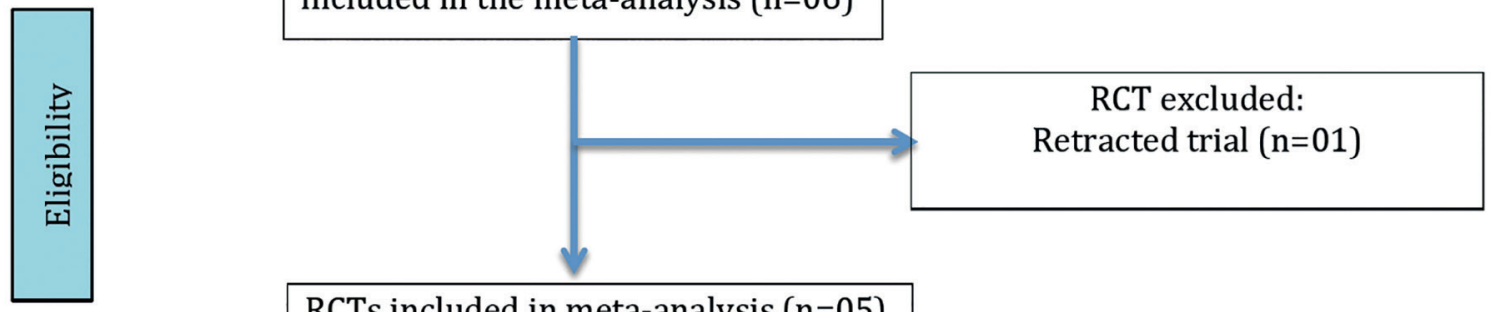

RCTs included in meta-analysis ( $\mathrm{n}=05)$
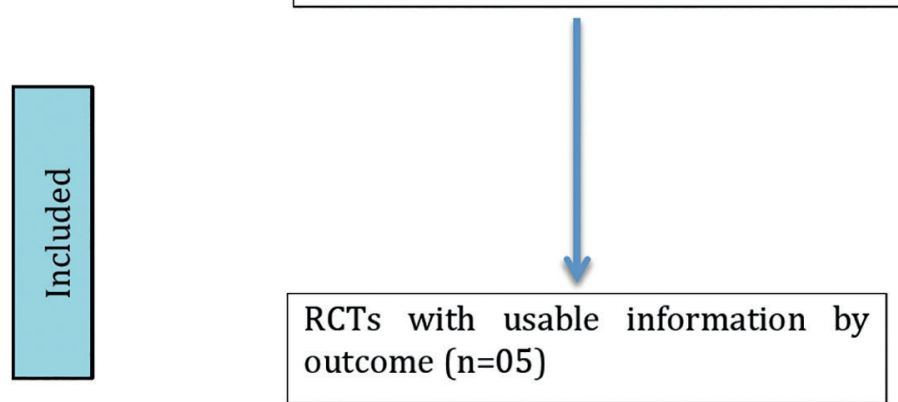

Figure 1. QUOROM statement flow diagram illustrating the selection of trials included in this meta-analysis.

computer-generated list. The sample size of 780 patients needed to achieve an $80 \%$ power for detecting a difference of $10 \%$ in ongoing pregnancy rates (there was no blind description). A total of 782 patients were included (391 in the Freeze/All-ET group and 391 in the Fresh-ET group). The primary outcome was ongoing pregnancy rates after the first embryo transfer. The baseline characteristics were similar between the groups, including age, stimulation

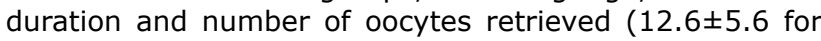
the cryopreservation group and $12.9 \pm 5.16$ for the fresh group). They found no difference between the Freeze/AllET and the Fresh-ET groups regarding ongoing pregnancy rates $(36.3 \%$ versus $34.5 \%$, respectively).

Coates et al., 2017: In this clinical trial, the aim was to identify which embryo transfer strategy, after preimplantation genetic screening (PGS) by next generation sequencing (NGS), freeze-all or Fresh-ET, would improve clinical outcomes or whether the strategies were equally successful. Women between the ages of 18 and 42 years, while undergoing IVF and PGS using their own eggs, were eligible to participate in the trial. The exclusion criteria included a need to use surgically retrieved sperm, patients using preimplantation genetic diagnosis for a single-gene or chromosomal disorder, egg donor cycles, gender selection cycles, decreased ovarian reserve (early follicular phase serum FSH level $>10 \mathrm{IU} / \mathrm{L}$ or random serum anti-Mullerian hormone level $<1 \mathrm{ng} / \mathrm{ml}$ ), and any medical conditions occurring before recruitment. A total of 179 patients were randomized to either a Freeze/All-ET cycle (91) or a Fresh-ET (88) on day 6 during the stimulated cycle. A professional third party prepared the stratified block randomization sequence. The allocation sequence 


\begin{tabular}{|c|c|c|c|c|c|}
\hline Study (RCTs) & $\begin{array}{c}\text { Women } \\
\text { (FET/Fresh-ET) }\end{array}$ & $\begin{array}{c}\text { Age, years } \\
\text { (FET/Fresh-ET) }\end{array}$ & $\begin{array}{c}\text { Mean number of } \\
\text { oocytes retrieved } \\
\text { (FET/Fresh-ET) }\end{array}$ & $\begin{array}{c}\text { Day of embryo } \\
\text { transfer }\end{array}$ & $\begin{array}{l}\text { Outcomes } \\
\text { measured }\end{array}$ \\
\hline Shapiro 2011a & $122(60 / 62)$ & $30.6 / 31.4$ & 20.9/19.3 & Day 5 & $\begin{array}{c}\text { Implantation } \\
\text { Clinical } \\
\text { pregnancy } \\
\text { Ongoing } \\
\text { pregnancy } \\
\text { Miscarriage }\end{array}$ \\
\hline Shapiro 2011b & $137(70 / 67)$ & $33.0 / 32.9$ & $12.9 / 14.1$ & Day 5 & $\begin{array}{c}\text { Implantation } \\
\text { Clinical } \\
\text { pregnancy } \\
\text { Ongoing } \\
\text { pregnancy } \\
\text { Miscarriage }\end{array}$ \\
\hline Chen 2016 & $1508(746 / 762)$ & $28.1 / 28.2$ & $14.4 / 14.2$ & $\begin{array}{l}\text { Day } 2 \\
\text { Day } 3 \\
\text { Day } 5\end{array}$ & $\begin{array}{c}\text { Biochemical } \\
\text { pregnancy } \\
\text { Clinical } \\
\text { pregnancy } \\
\text { Ongoing } \\
\text { pregnancy } \\
\text { Miscarriage } \\
\text { Live births }\end{array}$ \\
\hline Vuong 2016 & $782(391 / 391)$ & $31.8 / 32.1$ & $12.6 / 12.9$ & Day 3 & $\begin{array}{l}\text { Ongoing } \\
\text { pregnancy } \\
\text { Live birth }\end{array}$ \\
\hline Coates 2017 & $179(91 / 88)$ & $36.6 / 36.7$ & $14.0 / 17.0$ & Day 6 (PGS) & $\begin{array}{l}\text { Implantation } \\
\text { Ongoing } \\
\text { pregnancy } \\
\text { Live birth }\end{array}$ \\
\hline
\end{tabular}

was stratified for female age $(<35,35-37,38-40$, and $41-$ 42 years) and number of prior ART cycles ( $\leq 2$ or $\geq 3$ ). The women were randomized in a 1:1 ratio. The two groups were similar in age, anti-Mullerian hormone levels, FSH levels, mean number of oocytes retrieved (17.0 for Freeze/ All-ET group and 14.0 for Fresh-ET group), etc. Frozen ETs were performed in an artificial cycle, and Fresh-ET were carried out during original egg retrieval cycle. The outcome of patients in the intention-to-treat analysis were: ongoing pregnancy rates $(40.9 \%$ vs. $62.2 \% ; p<0.1)$ and live birth rates $(39.8$ vs. $61.5 \% ; p<0.1)$ per intended treatment was significantly higher for the freeze-all group compared with the fresh group.

\section{Quality assessment}

The methodological quality systems differ among the 5 RCTs. One trial did not have its complete data evaluated on methods ("non-randomized", "not-blind", "no-power calculation" descriptions) (Shapiro et al., 2011a). Randomization was done by drawing randomly among identical, opaque, unmarked sealed envelopes in one study (Shapiro et al., 2011b). In one study, the patients were randomly assigned to one of the two study groups in a $1: 1$ ratio, by an online central randomization system, which was unknown to the clinical investigators (Chen et al., 2016). Drawing randomly (1:1) was made by a computer-generated list in one study (Vuong et al., 2016). In one trial, a professional third party prepared the stratified block randomization sequence, and the allocation sequence was stratified for female age (Coates et al., 2017). Two studies described the method of blinding (Chen et al., 2016; Coates et al., 2017).

\section{Main outcomes}

The results of this meta-analysis were broken down into two parts, in accordance with the mean number of oocytes retrieved:

\section{I- Outcomes when $>12$ to $<21$ oocytes retrieved}

Clinical pregnancy rates (Figure 2)

To analyze clinical pregnancy rates (per randomized patient), 3 studies were included, and there were no significant differences between the Fresh-ET group: 55.1\%, (491/891) and the Freeze/All-ET group: 59.2\% (519/876) $(\mathrm{OR}=1.19 ; 95 \% \mathrm{CI}=0.98-1.43 ; p=0.09)$. There was no significant heterogeneity in this comparison: $\mathrm{I}^{2}=33.2 \%$; Cochran $\mathrm{Q}=2.99, p=0.22$.

\section{Ongoing pregnancy rates (Figure 3)}

To analyze ongoing pregnancy rates (per randomized patient), we included 5 studies and achieved significant differences between the groups: Fresh-ET: $44.1 \%$ (604/1370) versus Freeze/All-ET: 49.3\% (669/1358) $(\mathrm{OR}=1.24 ; 95 \% \mathrm{CI}=1.06-1.44 ; p=0.006)$. There was no significant heterogeneity in this comparison: $\mathrm{I}^{2}=46.5 \%$; Cochran $\mathrm{Q}=7.4, p=0.11$.

\section{Live birth rates (Figure 4)}

To analyze live birth rates (per randomized woman) we included 3 trials and no significant difference was found between the groups: Fresh-ET: $35.5 \%(440 / 1241)$ versus Freeze/All-ET: $41.8 \%(513 / 1228)(\mathrm{OR}=1.39 ; 95 \% \mathrm{CI}=0.99$ $1.95 ; p=0.06)$. There was an important heterogeneity in this comparison: $\mathrm{I}^{2}=64.1 \%$; Cochran $\mathrm{Q}=5.6 ; p=0.06$. 


\section{Odds ratio meta-analysis plot [fixed effects]}

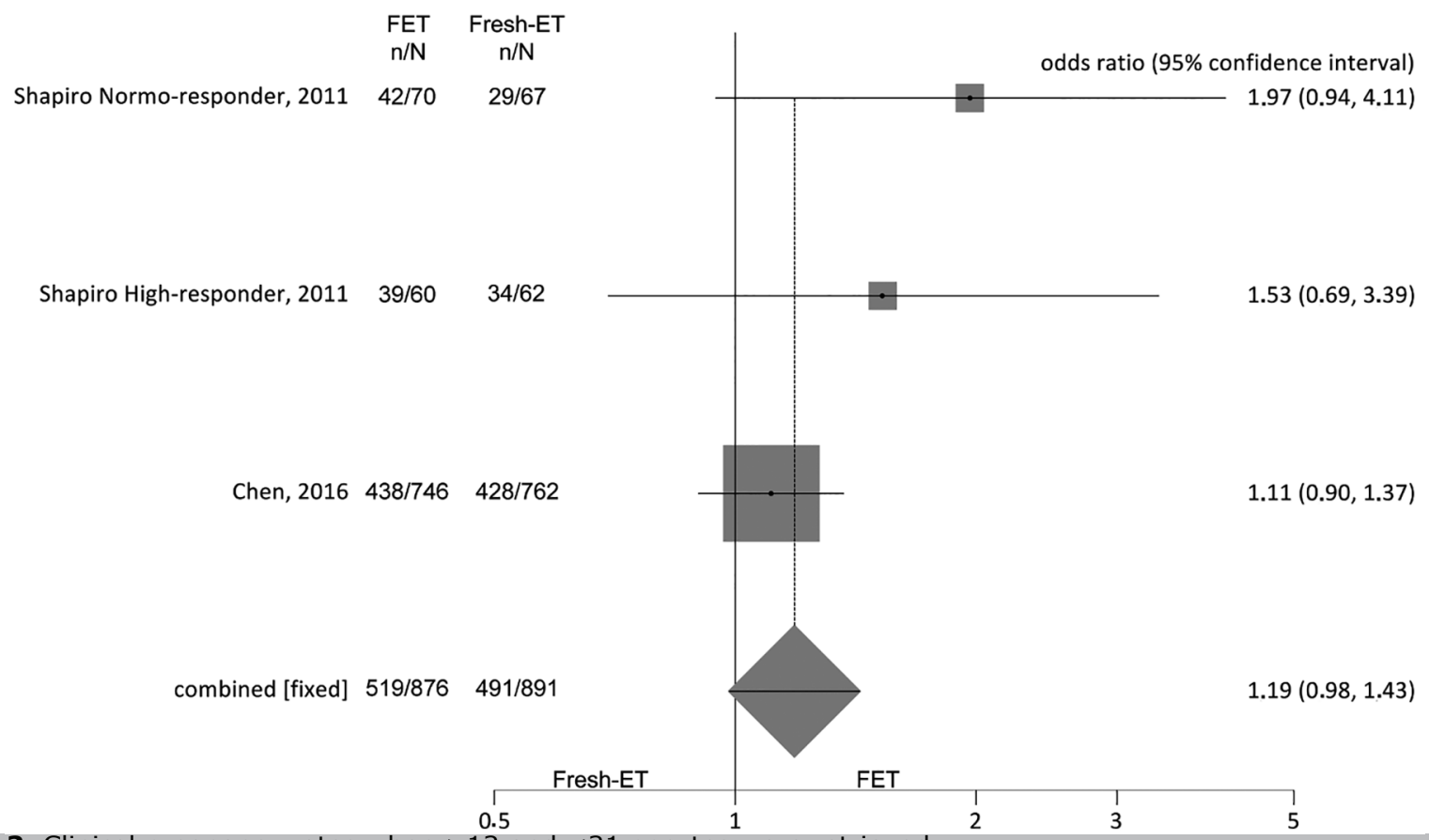

Figure 2. Clinical pregnancy rates when $>12$ and $<21$ oocytes were retrieved.

\section{Odds ratio meta-analysis plot [fixed effects]}

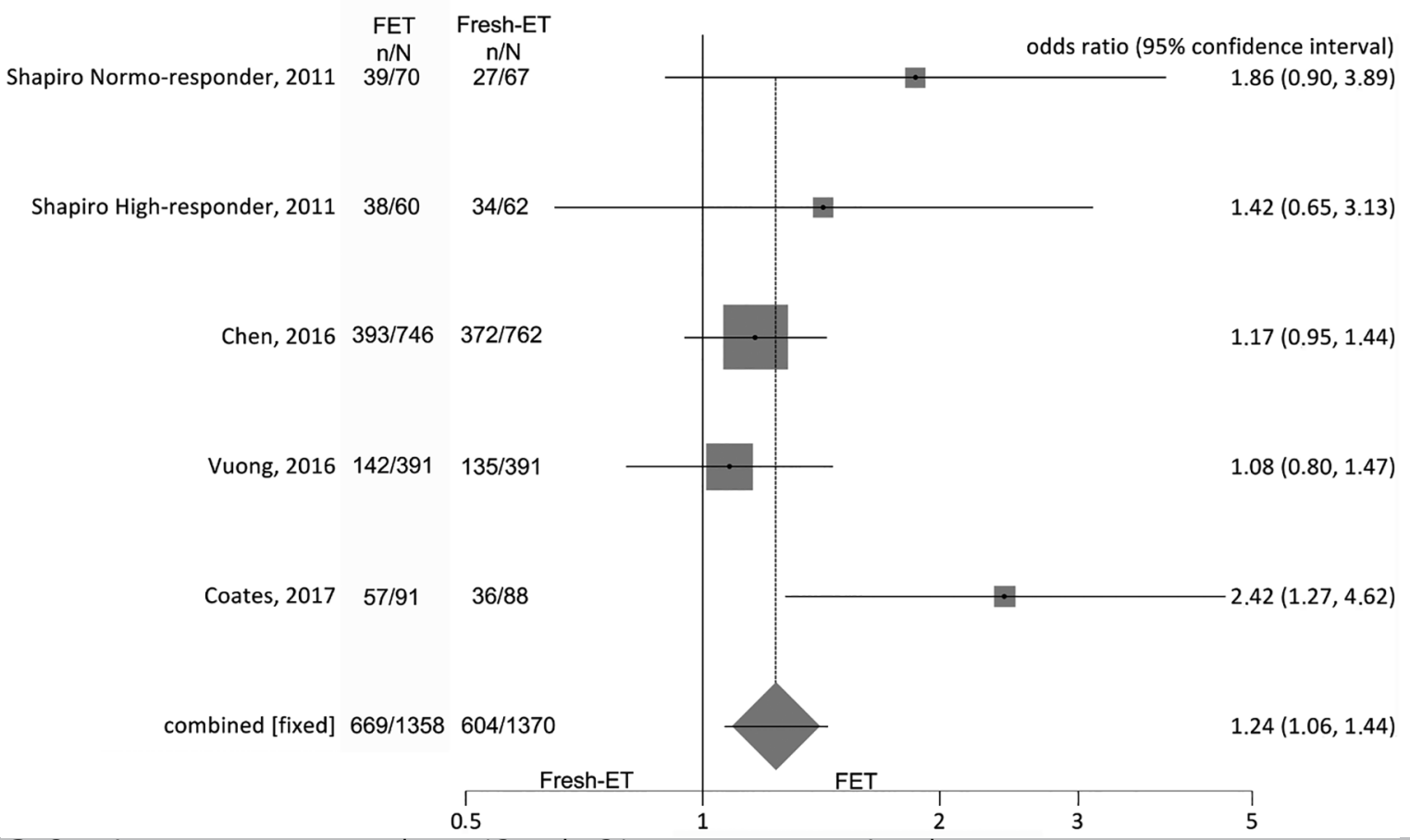

Figure 3. Ongoing pregnancy rates when $>12$ and $<21$ oocytes were retrieved.

Miscarriage rates

To analyze the rate of miscarriage (from clinical pregnancy), we considered 3 trials, and no significant difference was found between the groups: Fresh-ET: $13.8 \%$ (68/491) versus Freeze/All-ET: $10.0 \%$ (52/519) (OR=0.68; $95 \% \mathrm{CI}=0.46-1.00 ; p=0.06)$. There was no heterogeneity in this comparison: $\mathrm{I}^{2}=0 \%$; Cochran $\mathrm{Q}=0.21, p=0.90$.
II- Outcomes when $>12$ to $<15$ oocytes retrieved Clinical pregnancy rates (Figure 5)

For clinical pregnancy rates (per randomized patient) we included 2 studies, and no significant difference was found between the fresh and the cryopreservation groups: Fresh-ET group: $55.1 \%(457 / 829)$ versus Freeze/AllET group: $58.8 \%(480 / 816) \quad(\mathrm{OR}=1.34 ; 95 \% \mathrm{CI}=0.79-$ 


\section{Odds ratio meta-analysis plot [random effects]}

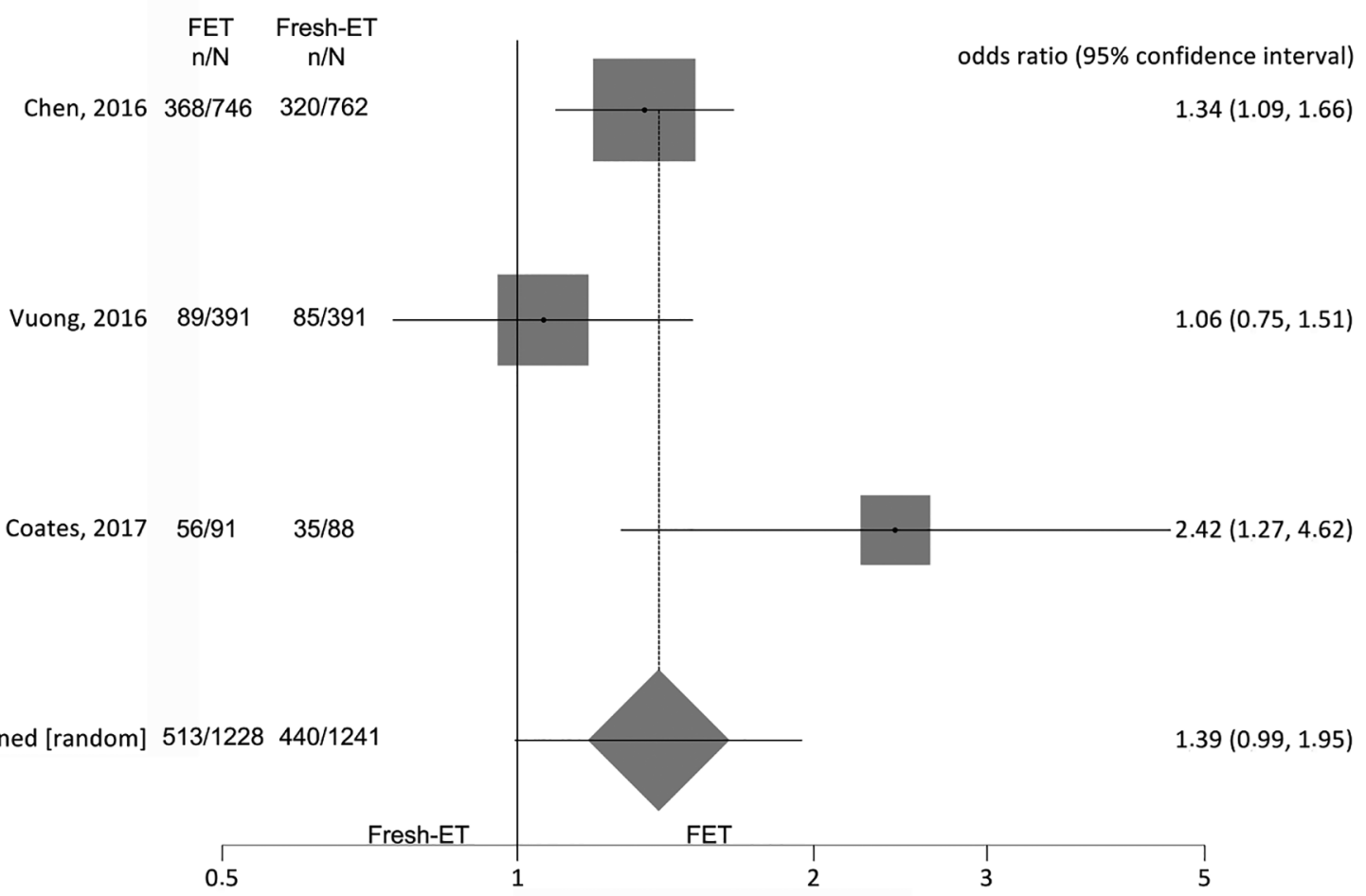

Figure 4. Live birth rates when $>12$ and $<21$ oocytes were retrieved.

\section{Odds ratio meta-analysis plot [random effects]}

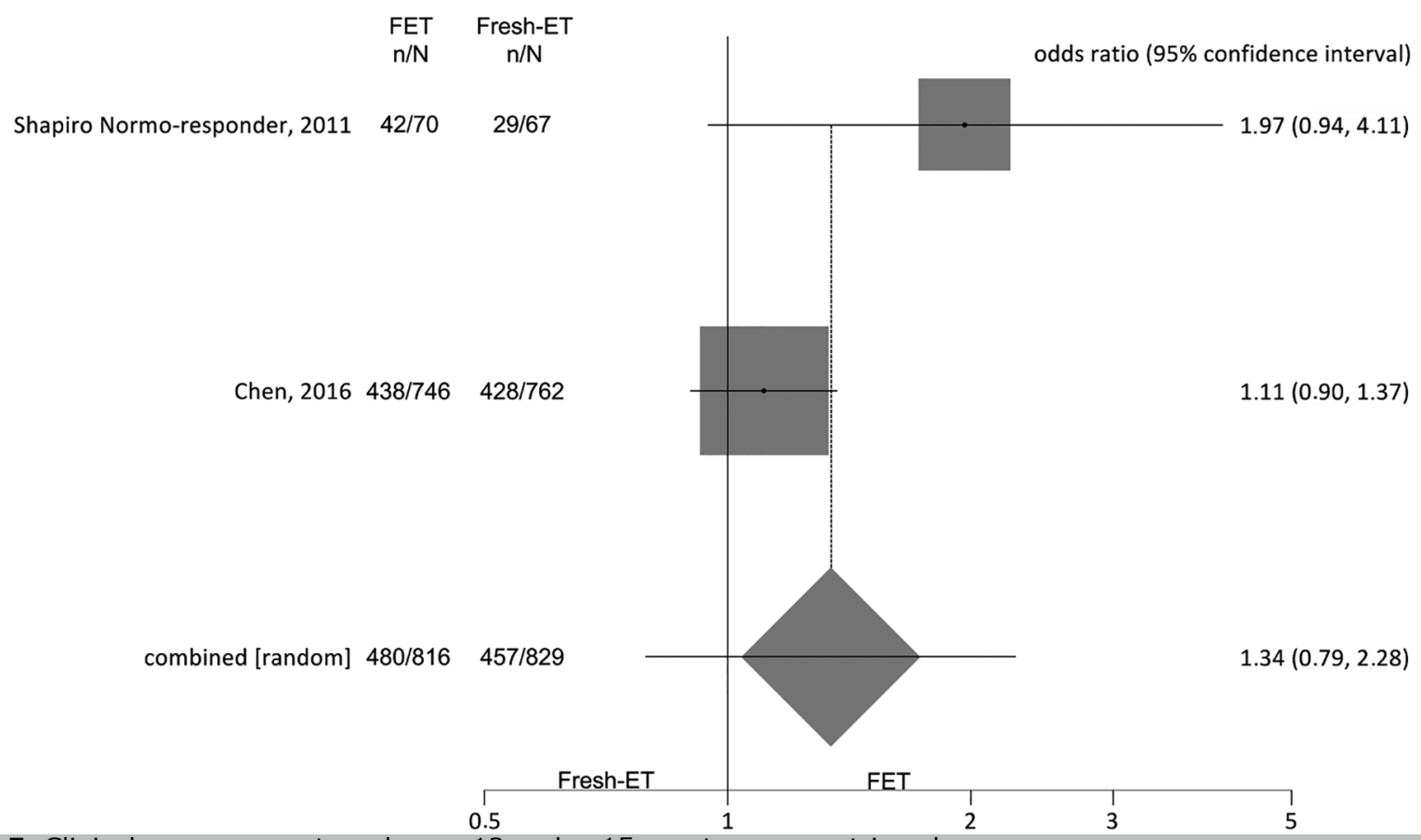

Figure 5. Clinical pregnancy rates when $>12$ and $<15$ oocytes were retrieved. 
$2.28 ; p=0.27)$. The heterogeneity was measured: $\mathrm{I}^{2}=\mathrm{NA}$; Cochran $\mathrm{Q}=2.5, p=0.11$.

\section{Ongoing pregnancy rates (Figure 6)}

For ongoing pregnancy rates (per randomized patient), we included 3 studies, and no significant difference was found between the groups: Fresh-ET group: $43.7 \%$ (534/1220) versus Freeze/All-ET group: $47.5 \%$ (574/1207) $(\mathrm{OR}=1.17 ; 95 \% \mathrm{CI}=1.00-1.38 ; p=0.06)$. There was no significant heterogeneity in this comparison: $\mathrm{I}^{2}=4.1 \%$; Cochran $\mathrm{Q}=2.1, p=0.4$.

\section{Live birth rates (Figure 7)}

To analyze live birth rates (per randomized woman) we included 2 studies, and no significant difference was found between the groups: Fresh-ET: $35.5 \%$ (405/1153) versus Freeze/All-ET: $41.8 \% \quad(457 / 1137) \quad(\mathrm{OR}=1.24$; $95 \% \mathrm{CI}=1.00-1.55 ; \quad p=0.05)$. The heterogeneity was measured: $\mathrm{I}^{2}=\mathrm{NA}$; Cochran $\mathrm{Q}=1.4 ; p=0.2$.

\section{Miscarriage rates}

For miscarriage rates (from clinical pregnancy) we included 3 studies, and no significant difference was found between the groups: Fresh-ET group: 13.8\% (63/457) versus Freeze/All-ET group: $10.0 \%(48 / 480)$ ( $R R=0.68$; $95 \% \mathrm{CI}=0.46-1.02 ; p=0.06)$. The heterogeneity was measured: Cochran $\mathrm{Q}=0.2, p=0.65$.

A summary of the results of the present meta-analysis comparing Freeze/All-ET and Fresh-ET strategies is depicted on Table 2, including all trials (when the mean number of oocytes collected was $>12$ and $<21$ ), and on Table 3 , including trials with the mean number of oocytes retrieved between $>12$ and $<15$.

\section{Publication bias}

In the present meta-analysis concerning the freezeall versus the fresh embryo transfers strategies, the publication biases were evaluated by Begg-Mazumdar $(p=0.82)$, and Egger's tests $(p=0.12)$. Visual inspection of Begg's funnel plots is available in the S1 Figure.

\section{DISCUSSION}

When there are uncertainties about a given medical question, a meta-analysis is an important tool, able to dissolve such problem. This analytical method consists of an approach in which different and independent studies are joined and the results are combined into a single common outcome. Compared with narrative reviews, meta-analyses have the great advantage of being less influenced by a reviewer's opinion, thus providing unbiassed conclusions. In addition, all the results can easily be recalculated and compared with the conclusions stated by the authors. Regarding endometrial receptivity, several procedures are being proposed to improve clinical outcomes in patients undergoing ART cycles, and the freeze-all strategy seems to be an important step in this direction (Shapiro et al., 2008; Shapiro et al., 2011a, 2011b; Chen et al., 2016; Vuong et al., 2016; Coates et al., 2017). This systematic review demonstrated that compared with Fresh-ET, the Freeze/All-ET brought about significant improvements to the ongoing pregnancy rates of patients submitted to ART procedures, when the mean number of oocytes collected was not limited to 15 , regardless of having patients with PCOS. However, the Freeze/All-ET does not bear advantages when compared with Fresh-ET, when the mean number of oocytes retrieved is less than 15 . These findings may be associated with the deleterious effects of COS on endometrial receptivity during ART cycles (Shapiro et al., 2011a; Chen et al., 2016).

There are several reasons that justify the employment of the freeze-all strategy, such as risk of ovarian hyper- stimulation syndrome (OHSS), inadequate endometrial thickness, previous assisted reproduction procedure failures, infertility related to endometriosis, and high risk of venous thrombosis during ART procedures. However, the main pathophysiologic mechanism involved in the selection of the freeze-all strategy seems to be a premature progesterone elevation during COS, resulting in an impaired-reception uterine environment (Shapiro et al., 2011b; Mohamed et al., 2011; Nelson, 2013).

There is evidence in the literature to support this negative relationship between COS and pregnancy rates, probably due to the presence of elevated serum $P$ and $E$ levels during the follicular phase, promoting premature luteinization $(\mathrm{PL})$, which occurrence is seen in up to $30 \%$ of IVF/ICSI cycles (Schoolcraft et al., 1991; Fanchin et al., 1993; Givens et al., 1994; Venetis et al., 2013). Possible explanations for PL occurrence, could be associated with the rising levels of $E$, that may induce increased LH secretion, able to stimulate granulosa cells to produce progesterone but unable to promote trigger ovulation (Ubaldi et al., 1995; Melo et al., 2006), and increases in the number of mature follicles with $17 \mathrm{~mm}$ or more (Peluso, 1990; Bosch et al., 2003; Glamočlija et al., 2005). In addition, increased concentration of estrogen during the follicular phase in COS, upregulates endometrial progesterone receptor expression in comparison with what happens in natural cycles, promoting advanced endometrial maturation (Koo et al., 2015). The success of ART cycles is dependent on the number and quality of oocytes and embryos, and endometrial receptivity (Schoolcraft et al., 1991; Kagawa et al., 1992; Silverberg et al., 1994; Sims et al., 1994; Bosch et al., 2003; Lai et al., 2009; Milachich \& Shterev, 2016). The main negative effect of $P$ elevation during ART procedures seems to be on endometrial receptivity (endometrial asynchrony), rather than on oocyte or embryo quality (Lu et al., 2016). This harmful effect of $P$ elevation on endometrial receptivity in patients undergoing fresh autologous IVF/ICSI cycles becomes more evident knowing that the highest pregnancy rates occur in fresh oocyte donation cycles, wherein the endometrium is artificially prepared, without deleterious COS effects (Legro et al., 1993; Silverberg et al., 1994; Shapiro et al., 2009).

In view of the plausible negative effects of COS, mainly in high-responders, it has been demonstrated that the Freeze/All-ET could be the better choice to improve clinical outcomes in patients with higher $\mathrm{P}$ levels (Shapiro et al., 2011a; Lu et al., 2016). However, Levi and collaborators (in a non-randomized study) suggested that in patients submitted to ART procedures with a mean number of oocytes collected greater than $15, \mathrm{COS}$ did not result in damage on endometrial receptivity, and the relative brief COS with reduced number of days of ovarian stimulation (8.4 days) could explain the reduced negative endometrial effect (Levi et al., 2001).

On the other hand, the RCTs on freeze-all strategy available in the literature do not differ vis-à-vis outcomes involving ongoing pregnancy rates per randomized patient in the group of women with a mean number of retrieved oocytes below 15 . Shapiro and collaborators demonstrated, in a prior RCT involving normal-responders, that ongoing pregnancy rates (per patient) was not higher in the group submitted to Freeze/All-ET, when compared with the group of patients in whom Fresh-ET was performed (Shapiro et al., 2011b). Also, agreeing with the outcomes of this systematic review, Vuong and collaborators showed that patients with a mean number of collected oocytes of approximately 13, did not benefit from the Freeze/All-ET (Vuong et al., 2016). Similarly, Chen and collaborators reported that the Freeze/All-ET group achieved higher, 


\section{Odds ratio meta-analysis plot [fixed effects]}

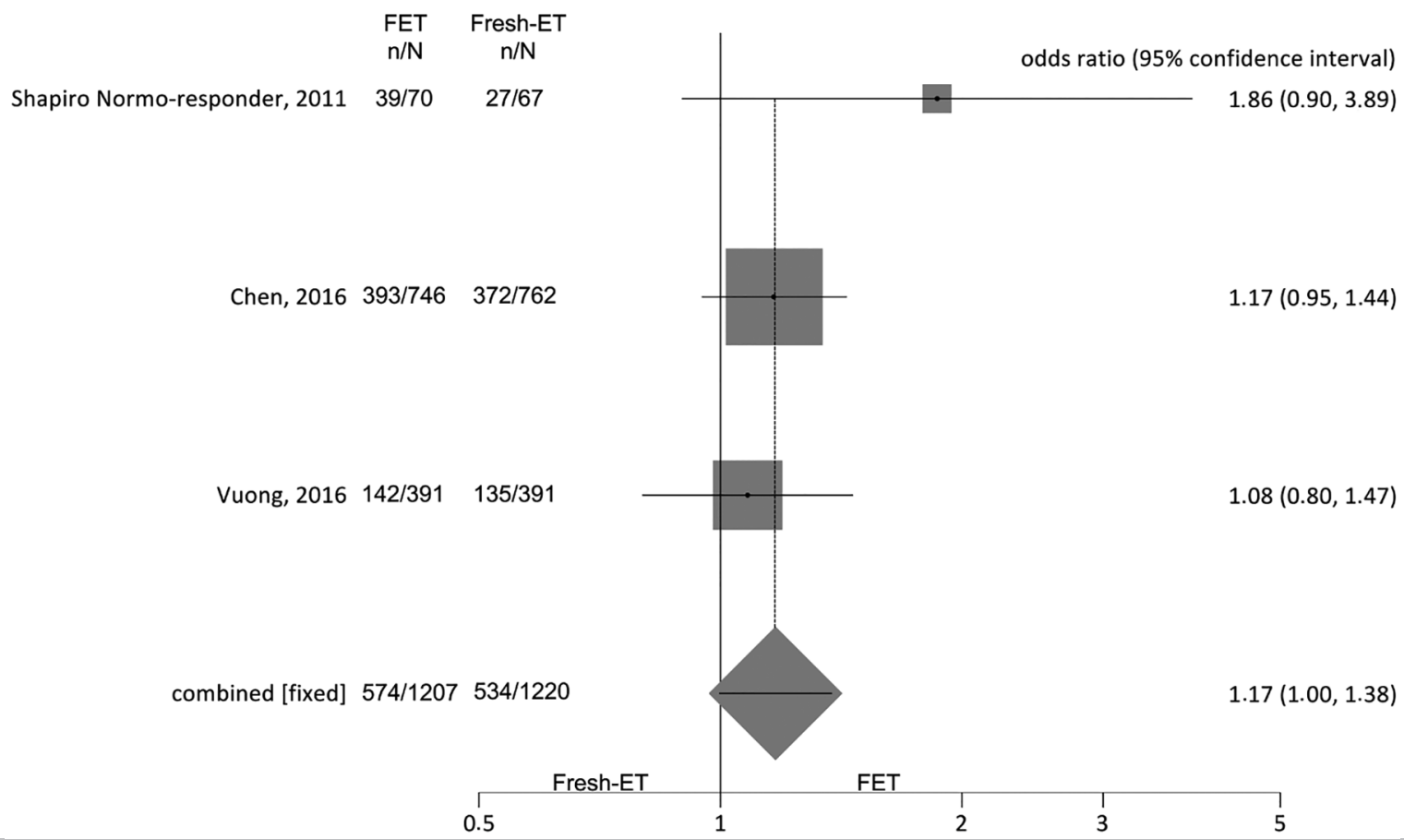

Figure 6. Ongoing pregnancy rates when $>12$ and $<15$ oocytes were retrieved.

\section{Odds ratio meta-analysis plot [random effects]}

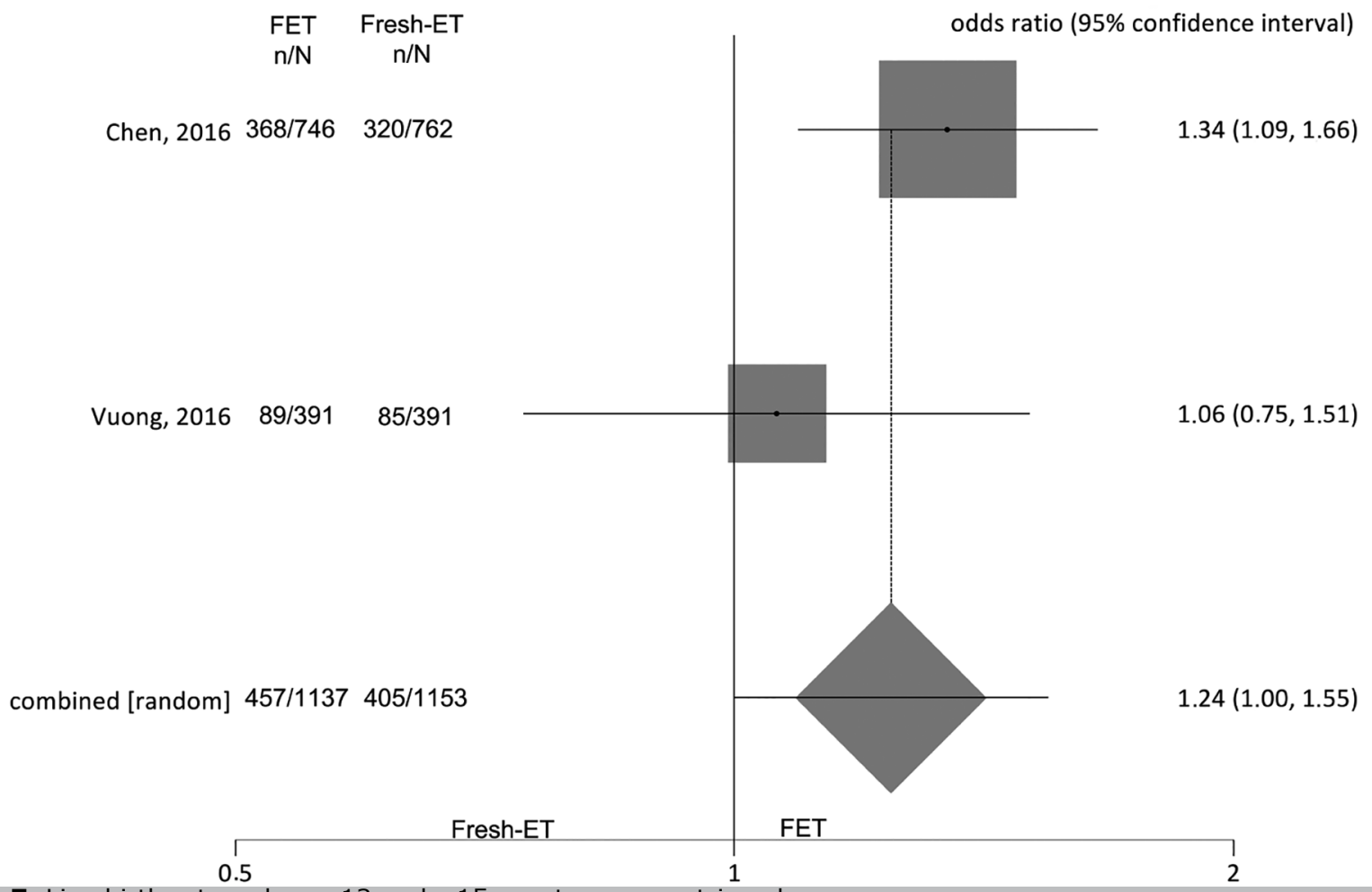

Figure 7. Live birth rates when $>12$ and $<15$ oocytes were retrieved. 
Table 2. Summary of the results: when the mean number of oocytes collected was $>12$ and $<21$

\begin{tabular}{|l|c|c|c|c|c|c|c|}
\hline $\begin{array}{l}\text { Outcome } \\
\text { measured }\end{array}$ & $\begin{array}{c}\text { No. } \\
\text { of patients }\end{array}$ & $\begin{array}{c}\text { Freeze/All-ET } \\
\text { group }\end{array}$ & $\begin{array}{c}\text { Fresh-ET } \\
\text { group }\end{array}$ & $\begin{array}{c}\text { Odds } \\
\text { ratio }\end{array}$ & $95 \%$ CI & $\begin{array}{c}\text { Analysis } \\
\text { model }\end{array}$ & $\begin{array}{c}\text { Heterogeneity } \\
\mathrm{I}^{2}\end{array}$ \\
\hline $\begin{array}{l}\text { Clinical } \\
\text { pregnancy }\end{array}$ & 1767 & 876 & 891 & 1.19 & $0.98-1.43$ & Fixed & $33.2 \%$ \\
\hline $\begin{array}{l}\text { Ongoing } \\
\text { pregnancy }\end{array}$ & 2728 & 1358 & 1370 & 1.24 & $1.06-1.44$ & Fixed & $46.5 \%$ \\
\hline Live birth & 2469 & 1228 & 1241 & 1.39 & $0.99-1.95$ & Random & $64.1 \%$ \\
\hline Miscarriage & 1010 & 519 & 491 & 0.68 & $0.46-1.00$ & Fixed & $0 \%$ \\
\hline
\end{tabular}

Table 3. Summary of the results: when the mean number of oocytes collected was $>12$ and $<15$

\begin{tabular}{|l|c|c|c|c|c|c|c|}
\hline $\begin{array}{l}\text { Outcome } \\
\text { measured }\end{array}$ & $\begin{array}{c}\text { No. of } \\
\text { patients }\end{array}$ & $\begin{array}{c}\text { Freeze/All-ET } \\
\text { group }\end{array}$ & $\begin{array}{c}\text { Fresh-ET } \\
\text { group }\end{array}$ & Odds ratio & $95 \%$ CI & $\begin{array}{c}\text { Analysis } \\
\text { model }\end{array}$ & Heterogeneity I $I^{2}$ \\
\hline $\begin{array}{l}\text { Clinical } \\
\text { pregnancy }\end{array}$ & 1645 & 816 & 829 & 1.34 & $0.79-2.28$ & Random & NA \\
\hline $\begin{array}{l}\text { Ongoing } \\
\text { pregnancy }\end{array}$ & 2427 & 1207 & 1220 & 1.17 & $1.00-1.38$ & Fixed & $4.1 \%$ \\
\hline Live birth & 2290 & 1137 & 1153 & 1.24 & $1.00-1.55$ & Random & NA \\
\hline Miscarriage & 937 & 480 & 457 & 0.68 & $0.46-1.02$ & Random & NA \\
\hline
\end{tabular}

but not significant ongoing pregnancy rates (per patient) (Chen et al., 2016).

A meta-analysis is a powerful tool, considered the highest in the evidence-based pyramid, but its strength depends on the quality of the randomized trials analyzed (Franco \& Oliveira, 2015). Recently, an RCT including high-responders, favoring the Freeze/All-ET strategy was retracted of the literature access (Aflatoonian et al., 2010). This retracted RCT is part of a relatively recent metaanalysis (Roque et al., 2013) concerning the beneficial effects of cryopreservation and subsequent FET. However, removing the aforementioned study, the prior metaanalysis (Roque et al., 2013) loses its power to assist in medical decision-making whether the Freeze/All-ET should be used or not in clinical practice.

The freeze-all strategy is a topic that has recently gained attention from clinicians and embryologists. However, although it has great relevance for advances in ART, more prospective and randomized trials, involving large populations are necessary to define whether delayed frozen-thawed embryo transfer is beneficial, and for which groups of patients it could provide improvements in the clinical outcomes of IVF/ICSI cycles.

In conclusion, the findings of this meta-analysis suggest that the freeze-all strategy could be favorable when high numbers of oocytes are collected, signaling an association between higher COS and consequent impairment in endometrial receptivity. However, when the mean number of oocytes collected is less than 15, the freeze-all strategy does not appear to be advantageous. More RCTs are required to evaluate whether the freeze-all strategy could influence clinical outcomes.

\section{CONFLICT OF INTERESTS}

The authors have no conflicts of interest to report.

\section{Corresponding author:}

Jose Gonçalves Franco Jr

Center for Human Reproduction Prof. Franco Jr
Ribeirao Preto, SP, Brazil.

E-mail: crh@crh.com.br

\section{REFERENCES}

Aflatoonian A, Oskouian H, Ahmadi S, Oskouian L. Can fresh embryo transfers be replaced by cryopreservedthawed embryo transfers in assisted reproductive cycles? A randomized controlled trial. J Assist Reprod Genet. 2010;27:357-63. PMID: 20373015 DOI: 10.1007/s10815-010-9412-9. Retraction in: J Assist Reprod Genet. 2013;30:1245. PMID: 23975193 DOI: $10.1007 / \mathrm{s} 10815-013-0084-0$

Bosch E, Valencia I, Escudero E, Crespo J, Simón C, Remohí J, Pellicer A. Premature luteinization during gonadotropinreleasing hormone antagonist cycles and its relationship with in vitro fertilization outcome. Fertil Steril. 2003;80:1444-9. PMID: 14667881 DOI: 10.1016/j.fertnstert.2003.07.002

Chen ZJ, Shi Y, Sun Y, Zhang B, Liang X, Cao Y, Yang J, Liu J, Wei D, Weng N, Tian L, Hao C, Yang D, Zhou F, Shi J, Xu Y, Li J, Yan J, Qin Y, Zhao H, Zhang H, Legro RS. Fresh versus Frozen Embryos for Infertility in the Polycystic Ovary Syndrome. N Engl J Med. 2016;375:523-33. PMID: 27509101 DOI: $10.1056 /$ NEJMoa1513873

Coates A, Kung A, Mounts E, Hesla J, Bankowski B, Barbieri E, Ata B, Cohen J, Munné S. Optimal euploid embryo transfer strategy, fresh versus frozen, after preimplantation genetic screening with next generation sequencing: a randomized controlled trial. Fertil Steril. 2017;107:723-30.e3. PMID: 28139240 DOI: $10.1016 /$ j.fertnstert.2016.12.022

Fanchin R, de Ziegler D, Taieb J, Hazout A, Frydman R. Premature elevation of plasma progesterone alters pregnancy rates of in vitro fertilization and embryo transfer. Fertil Steril. 1993;59:1090-4. PMID: 8486179 DOI: $10.1016 / \mathrm{S} 0015-0282(16) 55933-0$ 
Franco JG Jr, Oliveira JB. The Impact of Meta-analyses on Medical Decisions. JBRA Assist Reprod. 2015;19:109-10. PMID: 27203087 DOI: 10.5935/1518-0557.20150024

Givens CR, Schriock ED, Dandekar PV, Martin MC. Elevated serum progesterone levels on the day of human chorionic gonadotrophin administration do not predict outcome in assisted reproduction cycles. Fertil Steril. 1994;62:10117. PMID: 7926111 DOI: $10.1016 /$ S0015-0282(16)57066-6

Glamočlija V, Vilović K, Saraga-Babić M, Baranović A, Sapunar D. Apoptosis and active caspase-3 expression in human granulosa cells. Fertil Steril. 2005;83:426-31. PMID: 15705385 DOI: 10.1016/j.fertnstert.2004.06.075

Griesinger G, von Otte S, Schroer A, Ludwig AK, Diedrich K, Al-Hasani S, Schultze-Mosgau A. Elective cryopreservation of all pronuclear oocytes after GnRH agonist triggering of final oocyte maturation in patients at risk of developing OHSS: A prospective, observational proof-of-concept study. Hum Reprod. 2007;22:1348-52. PMID: 17303632 DOI: $10.1093 /$ humrep/dem006

Griesinger G, Schultz L, Bauer T, Broessner A, Frambach T, Kissler S. Ovarian hyperstimulation syndrome prevention by gonadotropin-releasing hormone agonist triggering of final oocyte maturation in a gonadotropin-releasing hormone antagonist protocol in combination with a "freeze-all" strategy: a prospective multicentric study. Fertil Steril. 2011;95:2029-33, 2033.e1. PMID: 21371705 DOI: $10.1016 / j$.fertnstert.2011.01.163

Huang Y, Wang EY, Du QY, Xiong YJ, Guo XY, Yu YP, Sun YP. Progesterone elevation on the day of human chorionic gonadotropin administration adversely affects the outcome of IVF with transferred embryos at different developmental stages. Reprod Biol Endocrinol. 2015;13:82. PMID: 26238449 DOI: 10.1186/s12958-015-0075-3

Kagawa T, Yamano S, Nishida S, Murayama S, Aono T. Relationship among serum levels of luteinizing hormone, estradiol, and progesterone during follicle stimulation and results of in vitro fertilization and embryo transfer (IVF-ET). J Assist Reprod Genet. 1992;9:106-12. PMID: 1627924 DOI: $10.1007 / B F 01203748$

Kansal Kalra S, Ratcliffe SJ, Milman L, Gracia CR, Coutifaris C, Barnhart KT. Perinatal morbidity after in vitro fertilization is lower with frozen embryo transfer. Fertil Steril. 2011;95:548-53. PMID: 20663500 DOI: $10.1016 /$ j.fertnstert.2010.05.049

Kolibianakis E, Bourgain C, Albano C, Osmanagaoglu K, Smitz J, Van Steirteghem A, Devroey P. Effect of ovarian stimulation with recombinant follicle-stimulating hormone, gonadotropin releasing hormone antagonists, and human chorionic gonadotropin on endometrial maturation on the day of oocyte pick-up. Fertil Steril. 2002;78:1025-9. PMID: 12413988 DOI: $10.1016 /$ S0015-0282(02)03323-X

Koo HS, Cha SH, Kim HO, Song IO, Min EG, Yang KM, Park CW. A high response to controlled ovarian stimulation induces premature luteinization with a negative impact on pregnancy outcomes in a gonadotropin-releasing hormone antagonist cycle. Clin Exp Reprod Med. 2015;42:149-55. PMID: 26816874 DOI: 10.5653/cerm.2015.42.4.149
Lai TH, Lee FK, Lin TK, Horng SG, Chen SC, Chen YH, Wang PC. An increased serum progesterone-to-estradiol ratio on the day of human chorionic gonadotropin administration does not have a negative impact on clinical pregnancy rate in women with normal ovarian reserve treated with a long gonadotropin releasing hormone. Fertil Steril. 2009;92:508-14. PMID: 18701101 DOI: $10.1016 /$ j.fertnstert.2008.06.036

Legro RS, Ary BA, Paulson RJ, Stanczyk FZ, Sauer MV. Premature luteinization as detected by elevated serum progesterone is associated with a higher pregnancy rate in donor oocyte in-vitro fertilization. Hum Reprod. 1993;8:1506-11. PMID: 8253943 DOI: $10.1093 /$ oxfordjournals.humrep.a138288

Levi AJ, Drews MR, Bergh PA, Miller BT, Scott RT Jr. Controlled ovarian hyperstimulation does not adversely affect endometrial receptivity in in vitro fertilization cycles. Fertil Steril. 2001;76:670-4. PMID: 11591397 DOI: $10.1016 /$ S0015-0282(01)01988-4

Lu X, Chen Q, Fu Y, Ai A, Lyu Q, YP K. Elevated progesterone on the trigger day does not impair the outcome of Human Menotrophins Gonadotrophin and Medroxyprogesterone acetate treatment cycles. Sci Rep. 2016;6:31112. PMID: 27498612 DOI: $10.1038 /$ srep31112

Melo MA, Meseguer M, Garrido N, Bosch E, Pellicer A, Remohí J. The significance of premature luteinization in an oocyte-donation programme. Hum Reprod. 2006;21:15037. PMID: 16648153 DOI: $10.1093 /$ humrep/dei474

Milachich T, Shterev A. Are there optimal numbers of oocytes, spermatozoa and embryos in assisted reproduction? JBRA Assist Reprod. 2016;20:142-9. PMID: 27584608 DOI: 10.5935/1518-0557.20160032

Mohamed AM, Chouliaras S, Jones CJ, Nardo LG. Live birth rate in fresh and frozen embryo transfer cycles in women with endometriosis. Eur J Obstet Gynecol Reprod Biol. 2011;156:177-80. PMID: 21353737 DOI: $10.1016 /$ j.ejogrb.2011.01.020

Moher D, Liberati A, Tetzlaff J, Altman DG, The PRISMA Group (2009). Preferred Reporting Items for Systematic Reviews and Meta-Analyses: The PRISMA Statement. PLoS Med 6(7): e1000097 PMID: 19621072 DOI: $10.1371 /$ journal.pmed1000097 For more information, visit: www.prisma-statement.org

Murata $\mathrm{Y}$, Oku $\mathrm{H}$, Morimoto $\mathrm{Y}$, Tokuda $\mathrm{M}$, Murata $\mathrm{T}$, Sugihara K, Nagata F, Nakaoka Y, Fukuda A. Freeze-thaw programmes rescue the implantation of day 6 blastocysts. Reprod Biomed Online. 2005;11:428-33. PMID: 16274600 DOI: $10.1016 / S 1472-6483(10) 61134-0$

Nelson SM. Venous thrombosis during assisted reproduction: Novel risk reduction strategies. Thromb Res. 2013;131:S13. PMID: 23452730 DOI: $10.1016 / S 0049-3848(13) 00023-6$

Nikas G, Develioglu OH, Toner JP, Jones HW Jr. Endometrial pinopodes indicate a shift in the window of receptivity in IVF cycles. Hum Reprod. 1999;14:787-92. PMID: 10221715 DOI: $10.1093 /$ humrep/14.3.787 
Peluso JJ. Role of the amplitude of the gonadotropin surge in the rat. Fertil Steril. 1990;53:150-4. PMID: 2295335 DOI: $10.1016 / S 0015-0282(16) 53231-2$

Richter KS, Shipley SK, McVearry I, Tucker MJ, Widra EA. Cryopreserved embryo transfers suggest that endometrial receptivity may contribute to reduced success rates of later developing embryos. Fertil Steril. 2006;86:862-6. PMID: 16935284 DOI: $10.1016 / j$.fertnstert.2006.02.114

Roque M, Lattes K, Serra S, Solà I, Geber S, Carreras R, Checa MA. Fresh embryo transfer versus frozen embryo transfer in in vitro fertilization cycles: A systematic review and meta-analysis. Fertil Steril. 2013;99:156-62. PMID: 23040524 DOI: 10.1016/j.fertnstert.2012.09.003

Schoolcraft W, Sinton E, Schlenker T, Huynh D, Hamilton $\mathrm{F}$, Meldrum DR. Lower pregnancy rate with premature luteinization during pituitary suppression with leuprolide acetate. Fertil Steril. 1991;55:563-6. PMID: 1900481 DOI: 10.1016/S0015-0282(16)54186-7

Shapiro BS, Daneshmand ST, Garner FC, Aguirre M, Thomas S. Large blastocyst diameter, early blastulation, and low preovulatory serum progesterone are dominant predictors of clinical pregnancy in fresh autologous cycles. Fertil Steril. 2008;90:302-9. PMID: 17905239 DOI: 10.1016/j.fertnstert.2007.06.062

Shapiro BS, Daneshmand ST, Garner FC, Aguirre M, Hudson $C$, Thomas S. High ongoing pregnancy rates after deferred transfer through bipronuclear oocyte cryopreservation and post-thaw extended culture. Fertil Steril. 2009;92:1594-9. PMID: 19006793 DOI: 10.1016/j.fertnstert.2008.08.103

Shapiro BS, Daneshmand ST, Garner FC, Aguirre M, Hudson C, Thomas S. Evidence of impaired endometrial receptivity after ovarian stimulation for in vitro fertilization: a prospective randomized trial comparing fresh and frozen-thawed embryo transfers in high responders. Fertil Steril. 2011a;96:516-8. PMID: 21737071 DOI: $10.1016 / j$.fertnstert.2011.02.059
Shapiro BS, Daneshmand ST, Garner FC, Aguirre M, Hudson $C$, Thomas S. Evidence of impaired endometrial receptivity after ovarian stimulation for in vitro fertilization: a prospective randomized trial comparing fresh and frozen-thawed embryo transfer in normal responders. Fertil Steril. 2011b;96:344-8. PMID: 21737072 DOI: 10.1016/j.fertnstert.2011.05.050

Silverberg KM, Martin M, Olive DL, Burns WN, Schenken RS. Elevated serum progesterone levels on the day of human chorionic gonadotropin administration in in vitro fertilization cycles do not adversely affect embryo quality. Fertil Steril. 1994;61:508-13. PMID: 8137975 DOI: 10.1016/S0015-0282(16)56584-4

Sims JA, Seltman HJ, Muasher SJ. Early follicular rise of serum progesterone concentration in response to a flare-up effect of gonadotrophin-releasing hormone agonist impairs follicular recruitment for in-vitro fertilization. Hum Reprod. 1994;9:235-40. PMID: 8027278 DOI: $10.1093 /$ oxfordjournals.humrep.a138488

Ubaldi F, Smitz J, Wisanto A, Joris H, Schiettecatte J, Derde MP, Borkham E, Van Steirteghem A, Devroey P. Oocyte and embryo quality as well as pregnancy rate in intracytoplasmic sperm injection are not affected by high follicular phase serum progesterone. Hum Reprod. 1995; 10:3091-6. PMID: 8822420 DOI: 10.1093/oxfordjournals.humrep.a135864

Venetis CA, Kolibianakis EM, Bosdou JK, Tarlatzis BC. Progesterone elevation and probability of pregnancy after IVF: a systematic review and meta-analysis of over 60 000 cycles. Hum Reprod Update. 2013;19:433-57. PMID: 23827986 DOI: $10.1093 /$ humupd/dmt014

Vuong LT, Dang VQ, Ho TM, Huynh BG, Ha DT, Pham TD, Nguyen LK, Norman RJ, Mol BW. Freeze-all versus fresh embryo transfer in IVF/ICSI, a randomised controlled trial. Fertil Steril. 2016;106:e376. DOI: 10.1016/j.fertnstert.2016.08.006

Wong KM, Mastenbroek S, Repping S. Cryopreservation of human embryos and its contribution to in vitro fertilization success rates. Fertil Steril. 2014;102:19-26. PMID: 24890275 DOI: $10.1016 /$ j.fertnstert.2014.05.027 


\begin{tabular}{|c|c|c|}
\hline $\begin{array}{l}\text { Section / } \\
\text { topic }\end{array}$ & \# & Checklist item \\
\hline \multicolumn{3}{|l|}{ TITLE } \\
\hline Title & 1 & Identify the report as a systematic review, meta-analysis, or both. \\
\hline \multicolumn{3}{|l|}{ ABSTRACT } \\
\hline $\begin{array}{l}\text { Structured } \\
\text { summary }\end{array}$ & 2 & $\begin{array}{l}\text { Provide a structured summary including, as applicable: background; objectives; data } \\
\text { sources; study eligibility criteria, participants, and interventions; study appraisal and } \\
\text { synthesis methods; results; limitations; conclusions and implications of key findings; } \\
\text { systematic review registration number. }\end{array}$ \\
\hline \multicolumn{3}{|c|}{ INTRODUCTION } \\
\hline Rationale & 3 & Describe the rationale for the review in the context of what is already known. \\
\hline Objectives & 4 & $\begin{array}{l}\text { Provide an explicit statement of questions being addressed with reference to } \\
\text { participants, interventions, comparisons, outcomes, and study design (PICOS). }\end{array}$ \\
\hline \multicolumn{3}{|l|}{ METHODS } \\
\hline $\begin{array}{l}\text { Protocol and } \\
\text { registration }\end{array}$ & 5 & $\begin{array}{l}\text { Indicate if a review protocol exists, if and where it can be accessed (e.g., Web address), } \\
\text { and, if available, provide registration information including registration number. }\end{array}$ \\
\hline $\begin{array}{l}\text { Eligibility } \\
\text { criteria }\end{array}$ & 6 & $\begin{array}{l}\text { Specify study characteristics (e.g., PICOS, length of follow-up) and report } \\
\text { characteristics (e.g., years considered, language, publication status) used as criteria } \\
\text { for eligibility, giving rationale. }\end{array}$ \\
\hline $\begin{array}{l}\text { Information } \\
\text { sources }\end{array}$ & 7 & $\begin{array}{l}\text { Describe all information sources (e.g., databases with dates of coverage, contact with } \\
\text { study authors to identify additional studies) in the search and date last searched. }\end{array}$ \\
\hline Search & 8 & $\begin{array}{l}\text { Present full electronic search strategy for at least one database, including any limits } \\
\text { used, such that it could be repeated. }\end{array}$ \\
\hline $\begin{array}{l}\text { Study } \\
\text { selection }\end{array}$ & 9 & $\begin{array}{l}\text { State the process for selecting studies (i.e., screening, eligibility, included in } \\
\text { systematic review, and, if applicable, included in the meta-analysis). }\end{array}$ \\
\hline $\begin{array}{l}\text { Data collection } \\
\text { process }\end{array}$ & 10 & $\begin{array}{l}\text { Describe method of data extraction from reports (e.g., piloted forms, independently, } \\
\text { in duplicate) and any processes for obtaining and confirming data from investigators. }\end{array}$ \\
\hline Data items & 11 & $\begin{array}{l}\text { List and define all variables for which data were sought (e.g., PICOS, funding sources) } \\
\text { and any assumptions and simplifications made. }\end{array}$ \\
\hline $\begin{array}{l}\text { Risk of bias } \\
\text { in individual } \\
\text { studies }\end{array}$ & 12 & $\begin{array}{l}\text { Describe methods used for assessing risk of bias of individual studies (including } \\
\text { specification of whether this was done at the study or outcome level), and how this } \\
\text { information is to be used in any data synthesis. }\end{array}$ \\
\hline $\begin{array}{l}\text { Summary } \\
\text { measures }\end{array}$ & 13 & State the principal summary measures (e.g., risk ratio, difference in means). \\
\hline $\begin{array}{l}\text { Synthesis of } \\
\text { results }\end{array}$ & 14 & $\begin{array}{l}\text { Describe the methods of handling data and combining results of studies, if done, } \\
\text { including measures of consistency }\left(\mathrm{e} . \mathrm{g} ., \mathrm{I}^{2}\right) \text { for each meta-analysis. }\end{array}$ \\
\hline $\begin{array}{l}\text { Risk of bias } \\
\text { across studies }\end{array}$ & 15 & $\begin{array}{l}\text { Specify any assessment of risk of bias that may affect the cumulative evidence } \\
\text { (e.g., publication bias, selective reporting within studies). }\end{array}$ \\
\hline $\begin{array}{l}\text { Additional } \\
\text { analyses }\end{array}$ & 16 & $\begin{array}{l}\text { Describe methods of additional analyses (e.g., sensitivity or subgroup analyses, meta- } \\
\text { regression), if done, indicating which were pre-specified. }\end{array}$ \\
\hline \multicolumn{3}{|l|}{ RESULTS } \\
\hline $\begin{array}{l}\text { Study } \\
\text { selection }\end{array}$ & 17 & $\begin{array}{l}\text { Give numbers of studies screened, assessed for eligibility, and included in the review, } \\
\text { with reasons for exclusions at each stage, ideally with a flow diagram. }\end{array}$ \\
\hline $\begin{array}{l}\text { Study } \\
\text { characteristics }\end{array}$ & 18 & $\begin{array}{l}\text { For each study, present characteristics for which data were extracted } \\
\text { (e.g., study size, PICOS, follow-up period) and provide the citations. }\end{array}$ \\
\hline $\begin{array}{l}\text { Risk of bias } \\
\text { within studies }\end{array}$ & 19 & $\begin{array}{l}\text { Present data on risk of bias of each study and, if available, any outcome level assessment } \\
\text { (see item 12). }\end{array}$ \\
\hline $\begin{array}{l}\text { Results of } \\
\text { individual } \\
\text { studies }\end{array}$ & 20 & $\begin{array}{l}\text { For all outcomes considered (benefits or harms), present, for each study: (a) simple } \\
\text { summary data for each intervention group (b) effect estimates and confidence intervals, } \\
\text { ideally with a forest plot. }\end{array}$ \\
\hline $\begin{array}{l}\text { Synthesis of } \\
\text { results }\end{array}$ & 21 & $\begin{array}{l}\text { Present results of each meta-analysis done, including confidence intervals and measures } \\
\text { of consistency. }\end{array}$ \\
\hline
\end{tabular}


Continued S1 File.

\begin{tabular}{|c|c|c|}
\hline $\begin{array}{l}\text { Risk of bias } \\
\text { across studies }\end{array}$ & 22 & Present results of any assessment of risk of bias across studies (see Item 15). \\
\hline $\begin{array}{l}\text { Additional } \\
\text { analysis }\end{array}$ & 23 & $\begin{array}{l}\text { Give results of additional analyses, if done (e.g., sensitivity or subgroup analyses, } \\
\text { meta-regression [see Item 16]). }\end{array}$ \\
\hline \multicolumn{3}{|l|}{ DISCUSSION } \\
\hline $\begin{array}{l}\text { Summary of } \\
\text { evidence }\end{array}$ & 24 & $\begin{array}{l}\text { Summarize the main findings including the strength of evidence for each main outcome; } \\
\text { consider their relevance to key groups (e.g., healthcare providers, users, and policy makers). }\end{array}$ \\
\hline Limitations & 25 & $\begin{array}{l}\text { Discuss limitations at study and outcome level (e.g., risk of bias), and at review-level } \\
\text { (e.g., incomplete retrieval of identified research, reporting bias). }\end{array}$ \\
\hline Conclusions & 26 & $\begin{array}{l}\text { Provide a general interpretation of the results in the context of other evidence, and } \\
\text { implications for future research. }\end{array}$ \\
\hline \multicolumn{3}{|l|}{ FUNDING } \\
\hline Funding & 27 & $\begin{array}{l}\text { Describe sources of funding for the systematic review and other support (e.g., supply } \\
\text { of data); role of funders for the systematic review. }\end{array}$ \\
\hline
\end{tabular}

From: Moher et al., 2009. For more information, visit: www.prisma-statement.org

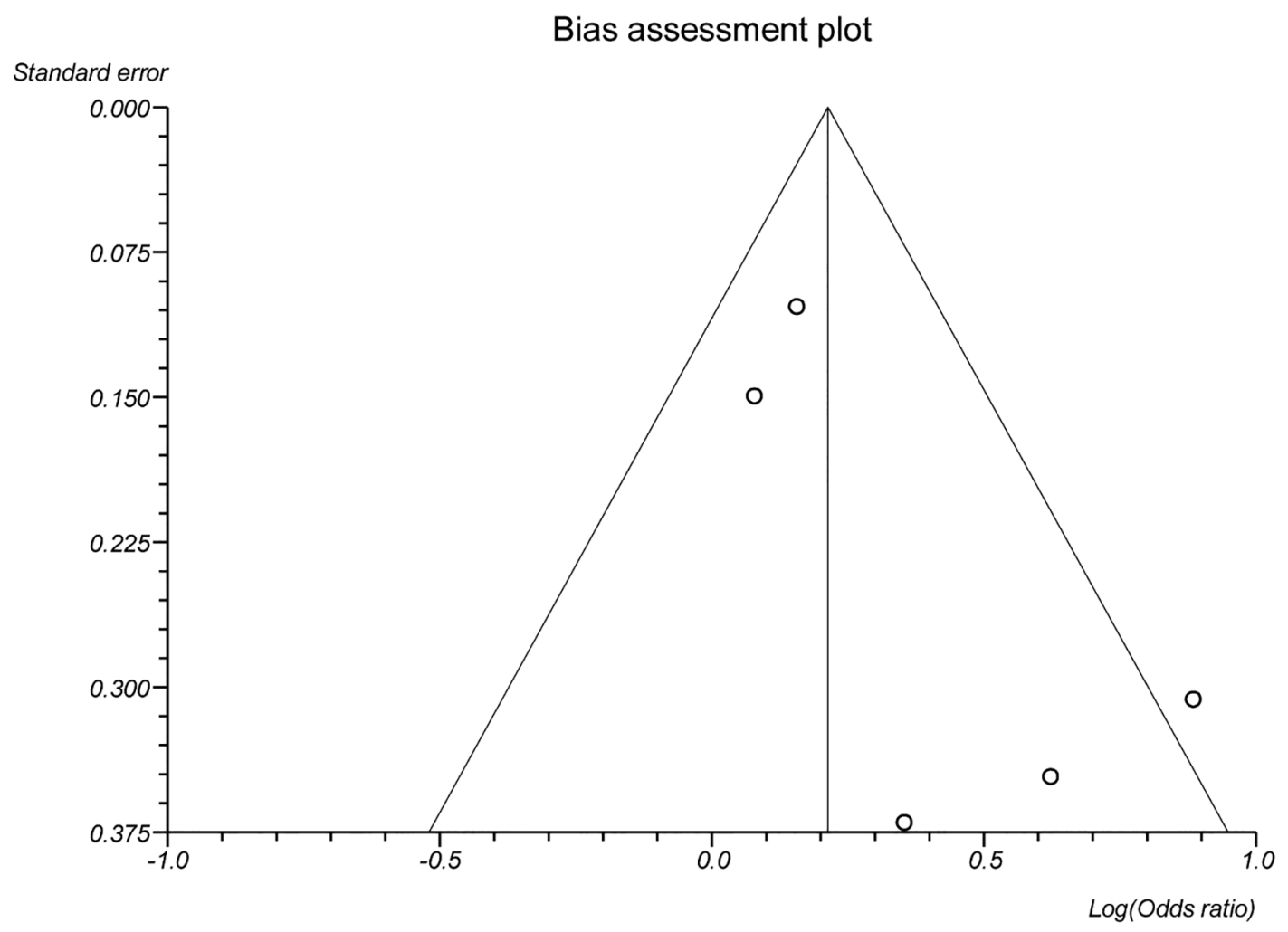

S1 Figure. Beeg's funnel plots (Publication Bias). 